\title{
Islet Encapsulation: Strategies to Enhance Islet Cell Functions
}

\author{
JONATHAN BECK, ${ }^{1,2}$ RYAN ANGUS, ${ }^{1}$ BEN MADSEN, ${ }^{1}$ DAVID BRITT, ${ }^{1}$ \\ BRENT VERNON, ${ }^{3}$ and KYTAI T. NGUYEN ${ }^{1,4}$
}

\begin{abstract}
Diabetes is one of the most prevalent, costly, and debilitating diseases in the world. Although traditional insulin therapy has alleviated the short-term effects, long-term complications are ubiquitous and harmful. For these reasons, alternative treatment options are being developed. This review investigates one appealing area: cell replacement using encapsulated islets. Encapsulation materials, encapsulation methods, and cell sources are presented and discussed. In addition, the major factors that currently limit cell viability and functionality are reviewed, and strategies to overcome these limitations are examined. This review is designed to introduce the reader to cell replacement therapy and cell and tissue encapsulation, especially as it applies to diabetes.
\end{abstract}

\section{INTRODUCTION}

D IABETES MELlitus, one of the most prevalent and destructive diseases in the world, affects more than 150 million individuals. It is the sixth leading cause of death in the United States, contributing to more than 200,000 deaths each year. In addition to the fatality rate, the cost associated with this disease is in excess of $\$ 105$ billion annually in the United States, and one in four Medicare dollars goes toward diabetes and its associated complications. ${ }^{1}$ Diabetes is also becoming more prevalent; the incidence of diabetes has increased $61 \%$ since 1991. The increasing prevalence, as seen in Figure 1, and the tremendous cost of diabetes are driving innovative research at the frontiers of medicine and bioengineering, warranting a review of the history, current status, and nearterm outlook for diabetes treatment.

In 1921, when Fredrick Banting and Charles Best discovered insulin, many believed that the deleterious effects of diabetes would be eliminated. Unfortunately, the availability of insulin was not sufficient to meet the demand, but as production of insulin increased, there was renewed optimism that diabetes could be curtailed. ${ }^{2}$ Although insulin therapy has significantly reduced the immediate risks of diabetes, the chronic effects of diabetes are increasingly problematic. With the use of insulin therapy, diabetic patients can live longer, but chronic complications prevail as the primary cause of morbidity and mortality. These complications include cardiovascular diseases, renal failure, amputations, and blindness. Studies have shown that intensive control of hyperglycemia, through strict dietary adherence and precise insulin therapy, can reduce the occurrence or progression of diabetic complications; ${ }^{3}$ however, tight control of blood glucose levels using existing treatments is difficult. ${ }^{4}$ Consequently, tremendous resources are being directed toward developing improved treatment options for individuals with diabetes.

Current therapies for diabetic patients at early stages include insulin injections, dietary restrictions, and exercise, whereas therapies for diabetic patients with severe symptoms involve transplantation of the entire pancreas (organ transplantation) or of purified islets (cell transplantation). The complications associated with transplantation, such as surgical morbidity and chronic immuno-suppression, however, must be considered and compared with the potential benefit of improved glucose metabolism. Several advanced

\footnotetext{
${ }^{1}$ Department of Biological and Irrigation Engineering, Utah State University, Logan, Utah.

${ }^{2}$ Department of Biomedical Engineering, University of Michigan, Ann Arbor, Michigan.

${ }^{3}$ Harrington Department of Bioengineering, Arizona State University, Tempe, Arizona.

${ }^{4}$ Department of Bioengineering, Joint Biomedical Engineering Program, University of Texas at Arlington and University of Texas Southwestern Medical Center at Dallas, Arlington, Texas.
} 
technologies, such as enclosed insulin-delivery systems and gene therapy, have also been developed to more effectively treat diabetes, 5 offering alternatives to the traditional treatments of insulin injections and diet. The reader is referred to several recent review papers on diabetes treatment through gene therapy $^{5-9}$ and closed-loop insulin-delivery systems, ${ }^{10-14}$ allowing this review to focus primarily on a promising bioengineering approach, islet encapsulation, for restoring normoglycemia through islet transplantation. ${ }^{15}$

\section{ISLET TRANSPLANTATION}

Islet transplantation involves the transfer of healthy islet cells from a donor to the diabetic patient. The advantages of islet transplantation over whole-organ, or pancreatic, transplantation are the elimination of major surgery, the reduced mass at transplantation time (beta-cells are about $1 \%$ of the total pancreas weight), and the potential storage of donor cells by cryopreservation. Although islet transplantation has been shown to control glucose levels successfully, there are several drawbacks involved with this procedure. The major obstacles to islet transplantation are the availability of islets and the maintenance of islet functions such as cell growth and survival. For instance, islet cells, unlike other cell types, cannot be expanded in vitro to provide sufficient cells for transplantation. Islet cells also tend to clump together, causing the core cells to die because of the limitation of nutrient transport to the aggregate center, which subsequently reduces cell functional replacement. Another obstacle to islet transplantation is the host rejection of implanted islets. Thus, patients are required to take lifelong immuno-suppressive drugs to overcome the rejection of transplanted islet cells. This raises the question of whether islet transplantation is preferable to continuous insulin treatment.

One approach to overcome these obstacles is islet encapsulation. ${ }^{16,17}$ Islet encapsulation uses an immuno-protective biomaterial to create a permselective membrane around a group of islet cells. A device of this type is often referred to as a bioartificial pancreas. The membrane allows the islets to regulate blood glucose levels through insulin release while excluding, based on size, the larger proteins and cells of the immune system. Thus, encapsulation is designed to limit, and ideally eliminate, an immunological response to the non-host islet cells. Isolation of the islet cells from the human immune system may also make xeno-transplants possible, eliminating the supply problem that exists. This article will present the materials and cells used, methods that have been employed, and prospects for future developments with regard to islet cell encapsulation.

\section{ENCAPSULATION MATERIAL}

The encapsulation material must perform two vital functions - it must isolate the encapsulated islet cells from the immune system, and it must allow the transport of small molecules such as glucose and nutrients into the islets-in addition to permitting diffusion of insulin and waste products. The purpose of encapsulation is to reduce rejection of the insulin-producing cells by the immune system. However, if immuno-isolation is achieved at the cost of critically hindered mass transport of insulin, glucose, oxygen, and other necessary molecules, then cell death will occur, and the device will fail. Even if the molecular-weight cutoff is appropriate for these first two critical parameters, host protein adsorption and fibrous encapsulation could cause failure of the device. There are several important constraints on the material properties of the encapsulating matrix.

Several materials, including alginate and polysulphone (PS), have shown promise in sequestering the insulinproducing cells from immune-effector cells, the complement system, and immunoglobulins. ${ }^{18-21}$ Of these materials, alginate, a natural material derived from kelp, has been the most widely used, and islet capsules produced from this material are in clinical trials. ${ }^{22,23}$ Furthermore, various materials such as poly(ethylene glycol) (PEG) and poly-Llysine (PLL) have been incorporated into alginate to reduce plasma adsorption and to form semi-permeable membranes that permit nutrient and oxygen transport but limit immunogenic reactions. ${ }^{24}$ For example, Cui et al. demonstrated that grafting PEG chains onto alginate capsules increased in vivo viability of islet cells. ${ }^{25}$ PLL and poly-l-ornithine (PLO) have also been used to coat alginate islet beads to improve islet survival and to allow rapid removal of the systems. $^{19-21,26}$

In addition to alginate, PS has also been pursued as a possible encapsulation material. PS has a long history of use in renal dialysis and is readily fabricated as hollow fibers with a tight molecular-weight cutoff. Because PS is hydrophobic and adsorbs large amounts of insulin, work has been done to modify PS to render it more hydrophilic, allowing better insulin diffusion. However, blending PS with polyvinylpyrrolidone or sodium-dodecyl-sulfate interfered with proper islet function such as glucose-induced insulin release. ${ }^{27}$ On the other hand, hydroxy-methylated PS shows considerable promise as an encapsulation material because it does not limit the diffusion of insulin or alter insulin secretion of macroencapsulated islets. ${ }^{27}$ A combined "macroencapsulation" approach of filling PS hollow fibers with islet cells in an alginate matrix has shown promising results in diabetic rats up to 20 days. $^{28}$

In addition to alginate and PS, other materials such as PEG, dimethylaminoethyl methacrylate-methyl methacrylate copolymer, and poly(vinyl alcohol) have been used for islet encapsulation. Some of these materials, and the methods associated with their formation, are less than ideal because of reduced viability and functionality of the islet cells due to polymer biodegradation, permeability of the capsules, fragility, and limited surface area. ${ }^{29}$ Additionally, a few hydrogels use photo-initiation in the formation of the hydrogel, which may damage the encapsulated cells. ${ }^{30}$ Further- 


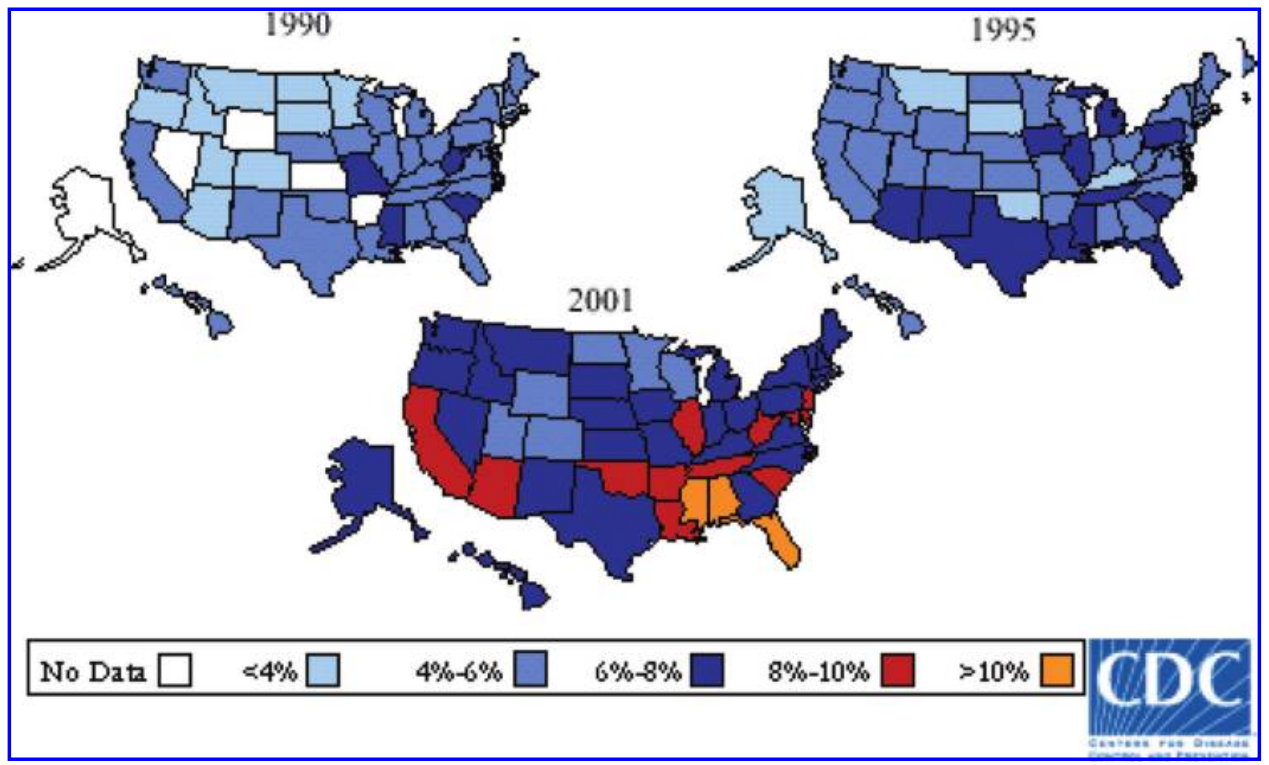

FIG. 1. Prevalence of diabetes in the United States; 1990, 1995, 2001.

more, amniotic membranes, nano-porous micro-systems, and silica have been evaluated as possible materials for encapsulation. ${ }^{31-33}$ It has also been proposed that a refillable synthetic extracellular matrix (ECM) could be constructed using a copolymer of poly(N-isopropyl-acrylamide) and acrylic acid. ${ }^{34} \mathrm{~A}$ bioartificial pancreas of this type would allow for infusion of additional islet cells if necessary.

Several materials have produced positive results, which illustrates the great promise of islet encapsulation. However, the properties and manufacturing methods of some materials may limit their use in the future. One limitation of all of these materials is their inability to prevent cytokine transfer across the membrane. ${ }^{32}$ This may not be crucial in autografts or allografts but would be an essential characteristic of an encapsulation material for use in xenografts. Selection of encapsulation material is vital, and as aforementioned, there are numerous materials being evaluated to determine the optimal materials and processing methods for islet encapsulation.

\section{CELLS USED FOR ENCAPSULATION}

The Islets of Langerhans are groups of cells in the pancreas that comprise four different cell types that produce the following hormones: glucagons ( $\alpha$ cells), insulin ( $\beta$ cells), somatostatin ( $\delta$ cells), and pancreatic polypeptide ( $\gamma$ cells). Like many terminally differentiated cells, pancreatic cells, especially $\beta$ cells, cannot be grown in vitro to provide sufficient cell mass for cell replacement. As a result, current islet transplants are dependent on allograft donors. $8,18,35,36$ Encapsulation of allograft islet cells must increase their survivability and functionality as well as reduce the need for immune suppression. In addition to improving allograft treatments, islet encapsulation presents the possibility of increasing the availability of donor cells by making xenografts and other cellular transplants possible.

Although there are several viable cell sources for islet encapsulation, human islet cells are an ideal choice for islet transplants. Recently, the first successful living-donor islet transplantation took place in Japan. ${ }^{37}$ Unfortunately, even with the advent of living-donor transplantations, the demand will still be far greater than the supply for the same reasons that the demand for kidney transplants is still much higher than the supply. To overcome the limited supply of $\beta$ cells, various sources for new $\beta$ cells have been investigated, including embryonic stem cells, adult stem cells, immortal islet cell lines, and xenografts. ${ }^{38}$

\section{Embryonic stem cells}

Because the mature islet cells do not readily divide, there is great interest in differentiating embryonic and adult stem, or precursor, cells into insulin-producing cells. ${ }^{39-44} \mathrm{Re}-$ cently, studies have succeeded in coaxing embryonic stem cells to produce insulin. ${ }^{45,46}$ The cells were able to assemble into 3-dimensional clusters, similar to those in vivo, and maintained pancreatic function, including glucose-induced insulin release. Factors used for stem cell differentiation include signals from blood vessels such as vascular endothelial growth factor A (VEGF-A) and fetal soluble factors, which play an important role in the pancreatic differentiation of embryonic stem cells. ${ }^{46-50}$ Additionally, undifferentiated embryonic stem cells are genetically engineered with $\beta$ cell genes such as Nkx6.1 to obtain insulin-secreting cells. $^{51,52}$ 


\section{Tissue progenitor/stem cells}

Insulin-producing cells can also be generated from adult stem cells as well as from embryonic stem cells. For instance, neural stem cells have demonstrated the ability to differentiate into cell clusters and to release insulin in response to glucose, similar to islets. ${ }^{53,54}$ Adult spleen cells also have been found to restore normoglycemia in diabetic mice. ${ }^{55}$ Although the adult stem cells lack the proliferative capabilities of embryonic stem cells, they may be safer because they would reduce the risk of uncontrolled proliferation in vivo, which might lead to cancer later. ${ }^{18}$ In addition, adult stem cells may make autologous cell transplants possible.

\section{Islet cell lines}

Because of the limited availability, difficulty, and expense of the isolation and differentiation of stem cells, islet cell lines have been explored as alternative cell sources for islet transplantation. Immortalized cell lines from endocrine precursor cells of the human pancreas, using retroviral vectors expressing multiple dominant oncogenes, have been developed to provide unlimited cell quantities for islet transplantation to treat diabetes. ${ }^{41,56}$ To address the problems that transformed cells grow indefinitely, develop large multi-cellular clusters, and force the encapsulated construct to expand and eventually rupture, growth-regulated cell lines have been generated by integrating tetracycline-off or -on operon systems to allow cell growth regulation upon exposure to tetracycline or its derivatives. ${ }^{18,57-59}$ Furthermore, the development of surrogate non-endocrine cells genetically modified to secrete insulin may provide an alternative source of cells that can regulate blood glucose levels. ${ }^{60-62}$

\section{Xenografts}

In addition to stem cells and cell lines generated from humans, islets isolated from other species are another source for $\beta$ cell replacement. ${ }^{63}$ Porcine islets are an attractive option for xeno-transplantation because of the high number of isolated cells and the ability for genetic modification. ${ }^{63}$ Before recombinant insulin-producing Escherichia coli, porcine insulin was often used in the treatment of diabetes. This suggests that, for most individuals, porcine insulin would effectively control blood glucose levels. One major drawback of xeno-transplantation is the need to use immunosuppression to prevent the destruction of pig islets by immunological processes when they are exposed to human blood. To protect islets from immune-mediated destruction, PEG derivatives have been used to modify the surface of adult porcine islets to provide an immuno-protection. ${ }^{29,64}$ Results from these studies have found that modification of porcine islets using PEG derivatives demonstrated significant in vitro and in vivo cyto-protection against immune reactions, potentially precluding the need for cell-mass encapsulation.
Despite the potential of xenografts, there are several major problems with using pig donors for islet transplantation. First, many individuals are opposed to this development, and some individuals may eschew treatment involving the use of cells derived from animal parts because of conflicts with their religious beliefs. ${ }^{65}$ Some are also against the use of trans-species islet transplants because of the fear of viral infection, particularly retroviruses. ${ }^{36,61}$ Viral infection is a risk to the general population, not just those who receive xenografts. For this reason, federal approval of xenografts presents a unique challenge. Furthermore, encapsulation of islets using a variety of biocompatible materials to avoid the hyper-immune response to xenografts has failed to maintain islet viability and secretory response. ${ }^{63}$ It is unlikely that xenografts will be widely used in clinical applications until these problems are overcome. Thus, insulin-producing cells derived from stem cells present a promising alternative posing less inherent risk.

\section{METHODS OF ENCAPSULATION}

There are three general encapsulation schemes that have been studied for islet transplantation. These include intravascular macrocapsules, extravascular macrocapsules, and microcapsules. In each case, a permselective membrane is used, with the molecular-weight cutoff dictating the immunoprotective properties of the immuno-barrier. Membrane chemistry and geometry are important aspects because they influence mass transport across the membrane, biocompatibility, and encapsulated cell viability.

An intravascular implant (Fig. 2A) is a perfusion chamber designed to be directly connected to the vascular system of the host via an arteriovenous shunt. ${ }^{66,67}$ In this system, blood flows through the lumen of the hollow fibers. Thus, the islets are in close proximity to the blood while being protected by the membrane. The design of this device provides better mass-transfer rates, which in turn augments transport of nutrients and oxygen to the islets using convective blood flow. Intravascular devices, however, have seen little success because of the risk of damaging a blood vessel during surgery and the formation of blood clots at the entrance and exit regions of the device. ${ }^{18}$

Macroencapsules (Fig. 2B) contain a large mass of islet cells within a diffusion chamber. Macroencapsulation devices are usually formed from spun coat membranes or spun drawn hollow fibers. Fiber diameter is an important factor to be considered when hollow fibers are used for encapsulation. A large-diameter fiber can result in a shorter overall length but can lead to nutrient diffusion limitations, thereby causing a central core of dead cells or necrotic tissue. In contrast, a small-diameter fiber can improve the transport of nutrients, but it can result in an extremely long fiber length, thereby increasing the potential breakage and making implantation more difficult. Extravascular macrocapsules can be implanted in the peritoneal cavity as well as subcutaneously. ${ }^{68}$ 


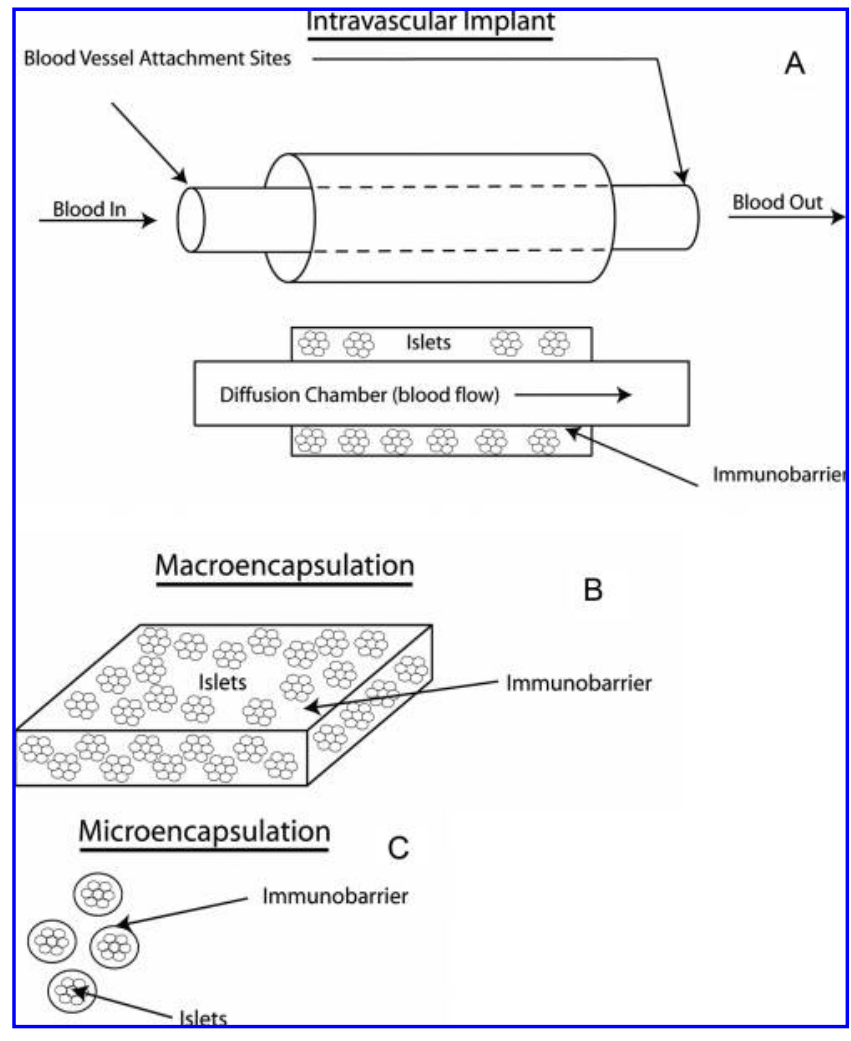

FIG. 2. Three schemes for encapsulating islet cells. (A) Intravascular implant, (B) macroencapsulation, (C) microencapsulation.

One advantage of extravascular macrocapsules is that they can be implanted and retrieved with minimal risk. However, their major drawback is the limitation of oxygen diffusion and nutrient transport, which dampens islet cell functions, including viability. ${ }^{18}$

Microencapsulation (Fig. 2C) is the encapsulation of single islets or small groups of islets. These capsules are usually spherical in shape. ${ }^{69}$ Several methods have been used in the production of islet microcapsules. These include double emulsion, photopolymerization, micro-machined nanoporous microsystems, and electrified coaxial liquid jets. ${ }^{32,70,71}$ Microcapsules offer the advantage of increased oxygen and nutrient transport due to the large surface area-to-volume ratio. The primary drawback of microencapsulation is the difficulty in removing the implants if necessary. The debate between macro- versus microencapsulation is an ongoing dispute, and neither technique has demonstrated clear superiority over the other.

\section{FACTORS INFLUENCING SURVIVABILITY AND FUNCTIONALITY}

Although islet cell transplantation is promising, the research has not progressed as quickly as was anticipated a decade ago. This is due, in part, to limited reproducibility of successful trials, as well as to the low survival rates and impaired functions of encapsulated islet cells. The primary causes of failure include hypoxia, limited diffusion at the transplantation site, biocompatibility of the encapsulating material, and insufficient immuno-protective properties of the immuno-barrier. ${ }^{72}$

\section{Hypoxia}

Hypoxia is a major limitation in islet cell therapy because islet cells need abundant amounts of nutrients and oxygen to function properly. Normal pancreatic blood flow ensures that islet cells, in their native physiological environment, receive sufficient quantities of nutrients and oxygen. ${ }^{17,73,74}$ Conversely, hypoxia can occur in transplanted islet cells because of limited diffusion through a permselective membrane. Hypoxia is most severe in areas furthest from the oxygen supply. In intravascular grafts, hypoxia most readily occurs at the perimeter of the device, whereas in extravascular macrocapsules and microcapsules, hypoxia is most problematic at the center of the cell mass.

Several methods have been investigated to reduce hypoxic stress in islet encapsulation. Heat shock, ischemic preconditioning, and stimulation of Bcl-2 and Bcl-xL before implantation may reduce the initial, but not long-term, hypoxic stress. ${ }^{75-77}$ There are also several proposed modalities for reducing chronic hypoxic stress. One proposed modality is the use of Brockman bodies. Brockman bodies are islet-like cells derived from tilapia fish accustomed to living in hypoxic water and therefore able to withstand low levels of oxygen. ${ }^{78}$ Pre-vascularization of the implant site, or of an implant matrix, may also decrease hypoxia. ${ }^{79}$ Factors that increase vascularization, such as VEGF, can be used to reduce hypoxic stress. ${ }^{80}$ Two other possibilities include genetic modification of insulin-producing cells and the production of smaller microcapsules. For instance, genes for hypoxia resistance could be transfected into insulinproducing cells, increasing the ability of the cells to withstand hypoxic conditions. Finally, the formation of smaller capsules will increase the surface-to-volume ratio, thereby reducing the distance the oxygen must diffuse to reach the center of the cell mass.

\section{Transplantation site}

It has been shown that the implantation site plays an important role in the hypoxic conditions, as well as the biocompatibility and survival of islets. For example, transplantation into the peritoneum exacerbates hypoxic conditions because oxygen is carried through the peritoneal cavity by passive diffusion only. ${ }^{81}$ This passive transport also limits the rate of insulin delivery from the islets, which hampers insulin secretory responses. ${ }^{81}$ The result is that $200 \%$ to $400 \%$ more islets must be implanted when the peritoneum is used as the transplant site. ${ }^{82}$ Additionally, the peritoneum site is proinflammatory for implantation of alginate-encapsulated pig islets, whereas kidney subcapsular and subcutaneous spaces 
improve biocompatibility and islet viability. ${ }^{83}$ The liver has also been investigated as a possible transplant site for islet microcapsules. ${ }^{84}$ It may be possible to transplant the islet microcapsules through an intra-portal injection, eliminating the need for surgical implantation of the encapsulated islets. ${ }^{85,86}$ For these reasons, many researchers are investigating extra-peritoneal sites for the transplantation of islet cells.

\section{Material biocompatibility}

Biocompatibility of the encapsulation material is also vital for proper in vivo function of the encapsulated islets. It has been shown that survival rates of encapsulated islets for allografts and autografts are similar. ${ }^{87}$ This would suggest that immune responses are not the only cause of failure. In fact, insufficient biocompatibility of the membrane leads to non-specific protein adsorption and fibrotic overgrowth of the capsules, which results in necrosis. ${ }^{87-91}$ Physical or chemical imperfections can cause necrosis, although physical imperfections account for fewer than $5 \%$ of these cases. ${ }^{72}$ It is important that the material selected for encapsulation be highly biocompatible. Thus, several strategies have been developed to improve the material biocompatibility. Of those, the addition of PEG chains to any encapsulation material will improve the biocompatibility of the membrane by reducing non-specific protein adsorption. ${ }^{92}$ The biocompatibility of alginate can also be increased through the removal of impurities from crude alginate. ${ }^{19}$

\section{Immuno-protection properties}

In addition to hypoxia and biocompatibility, the immunoprotective properties of the immuno-barrier are also important for the islet encapsulation process. Even in autografts, immune protection is necessary, because in type I diabetes, the immune system is responsible for the destruction of the original $\beta$ cells. Yet immune protection is more vital in allografts and especially in xenografts. When properly selected, the encapsulation material effectively sequesters the islet cells from the large molecules of the immune system, such as cells and antibodies. However, small molecules produced by the islets can attract macrophages, especially in xenografts, through chemotaxis. ${ }^{93}$ Chemotaxis may lead to fibrosis, a process whereby the host seeks to isolate the "foreign device" by walling it off with proteins and other materials. It has been shown that chemotaxis alone (without the involvement of hypoxia or biocompatibility) can lead to damage of the encapsulated islets. ${ }^{81}$ Chemoattractants, such as cytokines, can activate macrophages, which in turn produce nitric oxide. ${ }^{94,95}$ Nitric oxide is small enough to diffuse through the immuno-barrier and damage the islet cells. ${ }^{20}$ Therefore, several strategies have been developed to protect islets from nitric oxide-induced cellular damage. These strategies include co-encapsulation (with erythrocytes or Sertoli cells), addition of hemoglobin, and genetically en- gineering islet cells that are resistant to the deleterious effects of nitric oxide. ${ }^{96-102}$

\section{ADDITIONAL STRATEGIES TO INCREASE ISLET CELL SURVIVAL AND FUNCTION}

In the previous sections, several methods to increase the survivability and functionality of the encapsulated islets have been presented. These include methods for reducing hypoxia, selection of graft type (vascular, macro, or micro), selection of transplantation site, biomaterial selection and processing, and methods of increasing the immuno-protective properties of the immuno-barrier. To prevent islet necrosis and induce a longer survival rate and subsequent functional duration of a bioartificial pancreas, several additional strategies have been investigated. These strategies include the use of biological factors, surface modification of islet cells, novel methods of encapsulation, and ECM mimicry.

Several biological factors such as glucagon-like peptide- $1,{ }^{53}$ VEGF, ${ }^{27,103-106}$ and hepatocyte growth factor/scatter ${ }^{107,108}$ can be used to stimulate islet function. Other factors can also be used to create a more-conducive environment for transplantation. Many factors, such as VEGF, can increase vascularity at the transplantation site, thus increasing diffusion rates. These factors are incorporated with the encapsulated materials or delivered with islets at transplantation to enhance the functionality of islets.

It has also been proposed that surface modification, rather than encapsulation, may be sufficient to protect islets from host responses. This would create excellent diffusion rates, but it is unclear whether surface modification would provide suitable immuno-protection. Conjugating PEG onto the islet surfaces appears to increase islet cell survival in vivo, but the best results required the synergistic effects of cyclosporine A (a common immunosuppressant). ${ }^{109}$ Although PEGylation of islet cells improves cell survival, it is unlikely that it will prove effective in eliminating the need for immune suppression and would certainly be inadequate for xenotransplants.

Another approach to improving islet survival and function is to revisit the encapsulation paradigm. A novel and promising encapsulation method employs the use of a construct similar to a dialysis cartridge. ${ }^{116}$ A bioartificial pancreas constructed in this manner would provide greatly increased diffusion rates. It would also allow for the device to be explanted if necessary. Although the first-generation device of this design was tested extracorporeally, it is expected that future experiments will involve intravascular implantation. ${ }^{116}$ Despite some drawbacks, namely blood clotting, the preliminary results are promising. ${ }^{110}$

Although these different strategies may increase islet cell survival and function, it is important to note that the interactions between cells and their environment (integrin/ECM interaction) also play an important role in maintaining islet cell survival and function. Integrin/ECM interactions have been shown to affect islet cell adhesion, proliferation, and 
differentiation. For example, $\alpha_{\mathrm{v}} \beta_{3}$ and $\alpha_{\mathrm{v}} \beta_{5}$ regulate adhesion and differentiation of putative endocrine progenitor cells. ${ }^{111}$ The integrins, specifically $\alpha_{3} \beta_{1}$ and $\alpha_{6} \beta_{1}$, also regulate insulin secretion in part. ${ }^{86,112,113}$ Additionally, islets cultured on surfaces treated with anti- $\beta_{1}$ or anti- $\alpha_{1}$ antibodies show an increase in cell survival and glucose-stimulated insulin secretion. ${ }^{53,114-116}$ In addition to the use of integrin antibodies, ECM mimicry can be accomplished through incorporation of other ECM proteins and peptides.

It has been demonstrated that culturing islet cells on ECM-like surfaces increases islet survival and function. For instance, glucose-stimulated insulin secretion is greater when islets are cultured on surfaces treated with ECM molecules such as collagen type I or IV, laminin, fibronectin, or arginineglycine-aspartate (RGD) peptides. ${ }^{53,114-116}$ These findings indicate that incorporation of these ECM factors on the surface of the encapsulation material may improve islet survival and function. The exploitation of integrin/ECM interactions may also prove to be a vital element in creating a viable bioartificial pancreas.

Mimicking the pancreatic matrix membrane through incorporation of ECM molecules may be another means of increasing islet cell survival and function. Our preliminary studies indicated that islet cells adhered preferentially to cell-culture (polystyrene) surfaces coated with collagen IV (Fig. 3) and other molecules such as RGD, anti- $\alpha_{1}$, and anti$\beta_{1}$ (results not shown) in a dose-dependent manner. Of the molecules studied, collagen IV, anti- $\alpha_{1}$, and anti- $\beta_{1}$ appear to have the greatest effect on islet cell adhesion (Fig. 4).

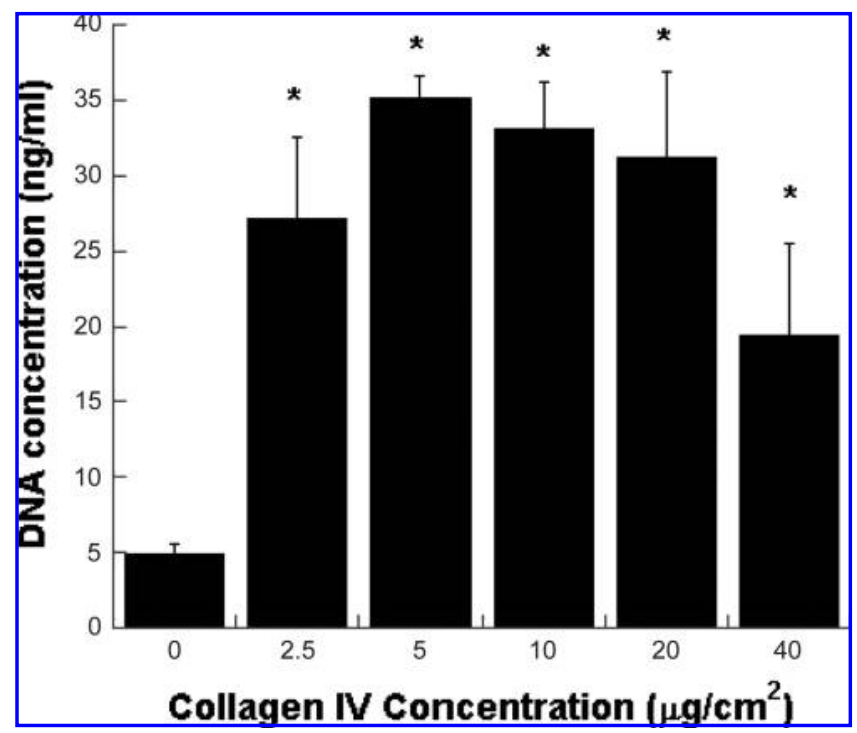

FIG. 3. Collagen IV enhanced the adhesion of islet cells in a dose-dependent manner. Various concentrations of collagen IV were used to coat the cell culture surfaces, and islet cell adhesion was determined using PicoGreen deoxyribonucleic acid (DNA) assays. Results are presented as mean \pm standard error of the mean $(n=6)$, and $*$ denotes significant difference compared with control samples (cell culture surfaces without coating).

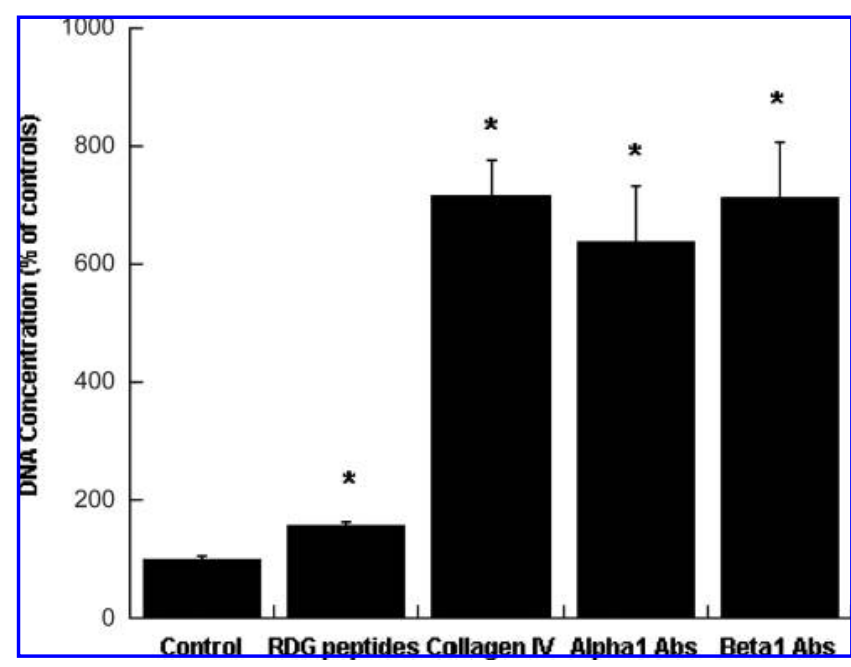

FIG. 4. Extracellular matrix molecules and integrin antibodies enhanced the capture of islets cells on the modified surfaces. Optimal concentrations of arginine-glycine-aspartate peptides $(10 \mu \mathrm{g} /$ $\left.\mathrm{cm}^{2}\right)$, collagen IV $\left(5 \mu \mathrm{g} / \mathrm{cm}^{2}\right)$, alpha1 antibodies $\left(1.2 \mu \mathrm{g} / \mathrm{cm}^{2}\right)$, and beta1 antibodies $\left(0.15 \mu \mathrm{g} / \mathrm{cm}^{2}\right)$ were used to coat the cell culture surfaces, and islet cell adhesion was determined using PicoGreen deoxyribonucleic acid (DNA) assays. Results are presented as mean \pm standard error of the mean $(n=6)$, and $*$ denotes significant difference compared with control samples (cell culture surfaces without coating).

Passive absorption of collagen IV onto PS and PS with polyvinyl pyrrolidone membranes also induced islet cell adhesion (Fig. 5). However, this induction was not as substantial as those seen on the polystyrene surfaces. Future

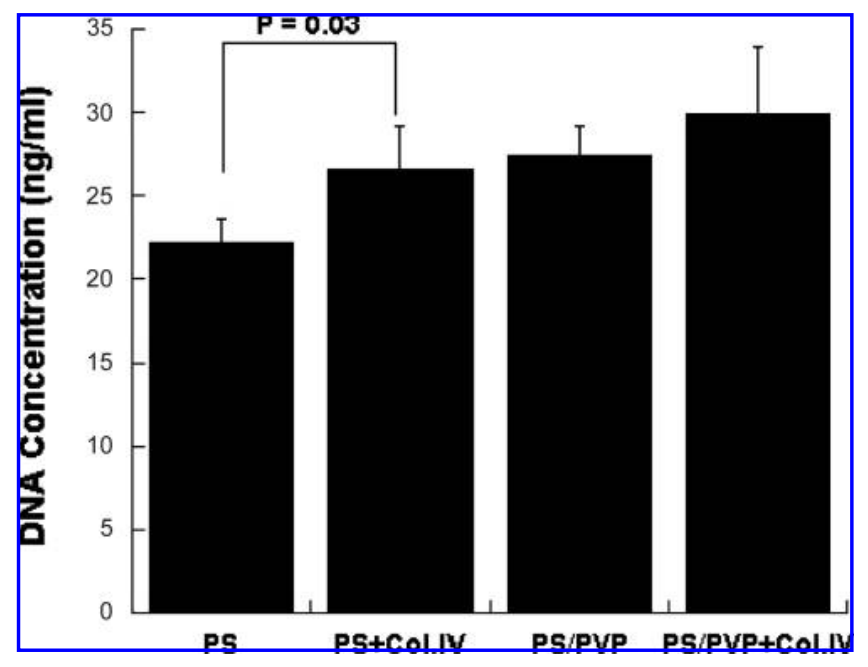

FIG. 5. Collagen IV enhanced the capture of islet cells on the surfaces of polysulfone (PS). Collagen IV $\left(5 \mu \mathrm{g} / \mathrm{cm}^{2}\right)$ was used to coat the surfaces of PS and PS with polyvinyl pyrrolidone (PVP) membranes. After seeding for $4 \mathrm{~h}$, islet cell adhesion on each surface was determined using PicoGreen deoxyribonucleic acid (DNA) assays. Results are presented as mean \pm standard error of the mean $(n=6)$, and $*$ denotes significant difference compared with control samples (cell culture surfaces without coating). 
work should include additional incorporation techniques, for example, cross-linking or layer-by-layer surface modification to improve the binding of collagen IV to PS. Further studies to assess other islet cell functions, including glucosestimulated insulin release, will help to determine the efficacy of collagen IV incorporation.

\section{CONCLUSIONS AND OUTLOOK}

Islet encapsulation is designed to overcome two major obstacles to traditional islet transplantation: inadequate supply of islet cells and the need for patient immune suppression. The creation of a clinically successful bioartificial pancreas will require advances in several areas. Advances in biomaterials, cell sources (including stem cells), genetic engineering, growth factor delivery, and ECM mimicry will provide new and valuable tools in the quest to create a viable bioartificial pancreas.

Perhaps no area of cell therapy has been more thoroughly studied than islet transplantation. This presents unique opportunities and challenges. It is vital that collaboration and data analysis efforts increase. This work is already underway; in 2004 the Collaborative Islet Transplant Registry (CITR) was created. "The mission of CITR is to expedite progress and promote safety in islet/beta-cell transplantation through the collection, analysis, and communication of comprehensive and current data on all islet/beta-cell transplants performed in North America." 117 The CITR is one example of how collaborative efforts are being devoted to islet encapsulation; however, these efforts must be expedited.

Despite the challenges of islet encapsulation, the outlook is positive. The groundwork has been laid in laboratories and clinical trials. The cost and limitations of current treatments provide the motivation for modern technologies and novel strategies. Advances in various fields such as lithography and biomimetic materials already provide the necessary tools for islet encapsulation. It is expected that, before the close of this decade, a clinically successful bioartificial pancreas will be created. Clinical success will not only benefit millions of individuals with diabetes, but will also provide a road map for future bioartificial organs, including treatments for cancer, liver failure, hemophilia, Parkinson's disease, muscular dystrophy, and heart diseases.

\section{ACKNOWLEDGMENTS}

Funding from an Undergraduate Research and Creative Opportunities grant to Jonathan Beck and the Engineering Initiatives at the Utah State University was used to support the writing of this manuscript and work reported in it. We would also like to acknowledge support from Fresenius Medical Care, North America (Ben Madsen) and from NSFEEC award \#0431824 (David Britt, Kytai Nguyen).

\section{REFERENCES}

1. Olefsky, J.M. Prospects for research in diabetes mellitus. JAMA 2001;285(5):628-632.

2. Walsh, G. Biopharmaceuticals: recent approvals and likely directions. Trends Biotechnol 23, 553, 2005.

3. Deedwania, P.C., Fonseca, V.A. Diabetes, prediabetes, and cardiovascular risk: shifting the paradigm. Am J Med 118, 939, 2005.

4. Sheetz, M.J., King, G.L. Molecular understanding of hyperglycemia's adverse effects for diabetic complications. JAMA 288, 2579, 2002.

5. Jun, H.S., Yoon, J.W. Approaches for the cure of type 1 diabetes by cellular and gene therapy. Curr Gene Ther 5, 249, 2005.

6. Furlan, R., Butti, E., Pluchino S., et al. Gene therapy for autoimmune diseases. Curr Opin Mol Ther 6, 525, 2004.

7. Chuah, M.K. Cutting through the obstacles and resurrecting the promise of gene therapy. IDrugs 8, 818, 2005.

8. Giannoukakis, N., Trucco, M. Gene therapy for type 1 diabetes: a proposal to move to the next level. Curr Opin Mol Ther 7, 467, 2005.

9. Yechoor, V., Chan, L. Gene therapy progress and prospects: gene therapy for diabetes mellitus. Gene Ther 12, 101, 2005.

10. Catargi, B. Current status and future of implantable insulin pumps for the treatment of diabetes. Expert Rev Med Devices 1, 181, 2004.

11. Renard, E. Implantable closed-loop glucose-sensing and insulin delivery: the future for insulin pump therapy. Curr Opin Pharmacol 2, 708, 2002.

12. Chia, C.W., Saudek, C.D. Glucose sensors: toward closed loop insulin delivery. Endocrinol Metab Clin North Am 33, 175, 2004.

13. Steil, G.M., Panteleon, A.E., Rebrin, K. Closed-loop insulin delivery - the path to physiological glucose control. Adv Drug Deliv Rev 56, 125, 2004.

14. Steil, G.M., Rebrin, K. Closed-loop insulin delivery-what lies between where we are and where we are going? Expert Opin Drug Deliv 2, 353, 2005.

15. Soon-Shiong, P. Treatment of type I diabetes using encapsulated islets. Adv Drug Deliv Rev 35, 259, 1999.

16. Kizilel, S., Garfinkel, M., Opara, E. The bioartificial pancreas: progress and challenges. Diabetes Technol Ther 7, 968, 2005.

17. Antonios, G. Mikos MGPSKSLIRCT. Mini-review: islet transplantation to create a bioartificial pancreas. Biotechnol Bioeng 43, 673, 1994.

18. Efrat, S. Cell replacement therapy for type 1 diabetes. Trends Mol Med. 8, 334, 2002.

19. Kendall, W.F., Jr., Darrabie, M.D., El-Shewy, H.M., et al. Effect of alginate composition and purity on alginate microspheres. J Microencapsul 21, 821, 2004.

20. de Groot, M., Schuurs, T.A., Leuvenink, H.G., et al. Macrophage overgrowth affects neighboring nonovergrown encapsulated islets. J Surg Res 115, 235, 2003.

21. Ma, X., Vacek, I., Sun, A. Generation of alginate-poly-1lysine-alginate (APA) biomicrocapsules: the relationship between the membrane strength and the reaction conditions. Artif Cells Blood Substit Immobil Biotechnol 22, 43, 1994.

22. Korbutt, G.S., Mallett, A.G., Ao, Z., et al. Improved survival of microencapsulated islets during in vitro culture and enhanced 
metabolic function following transplantation. Diabetologia 47, 1810, 2004.

23. Orive G., Hernâandez, R.M., Rodrâiguez Gascâon, A., et al. History, challenges and perspectives of cell microencapsulation. Trends Biotechnol 22, 87, 2004.

24. Orive, G., Tam, S.K., Pedraz, J.L., et al. Biocompatibility of alginate-poly-1-lysine microcapsules for cell therapy. Biomaterials 27, 3691, 2006.

25. Cui, W., Barr, G., Faucher, K.M., et al. A membrane-mimetic barrier for islet encapsulation. Transplant Proc May 36, 1206, 2004.

26. Dusseault, J., Leblond, F.A., Robitaille, R., et al. Microencapsulation of living cells in semi-permeable membranes with covalently cross-linked layers. Biomaterials May 26, 1515, 2005.

27. Petersen, P., Lembert, N., Zschocke, P., et al. Hydroxymethylated polysulphone for islet macroencapsulation allows rapid diffusion of insulin but retains PERV. Transplant Proc 34, 194, 2002.

28. Figliuzzi, M., Cornolti, R., Plati, T., et al. Subcutaneous xenotransplantation of bovine pancreatic islets. Biomaterials 26, 5640, 2005.

29. Xie, D., Smyth, C.A., Eckstein, C., et al. Cytoprotection of PEG-modified adult porcine pancreatic islets for improved xenotransplantation. Biomaterials 26, 403, 2005.

30. Cruise, G.M., Hegre, O.D., Scharp, D.S., et al. A sensitivity study of the key parameters in the interfacial photopolymerization of poly(ethylene glycol) diacrylate upon porcine islets. Biotechnol Bioeng 57, 655, 1998.

31. Boninsegna, S., Bosetti, P., Carturan, G., et al. Encapsulation of individual pancreatic islets by sol-gel $\mathrm{SiO} 2$ : a novel procedure for perspective cellular grafts. J Biotechnol 100, 277, 2003.

32. Desai, T.A., West, T., Cohen, M., et al. Nanoporous microsystems for islet cell replacement. Adv Drug Deliv Rev 56, 1661, 2004.

33. Mahgoub, M.A., Ammar, A., Fayez, M., et al. Neovascularization of the amniotic membrane as a biological immune barrier. Transplant Proc 36, 1194, 2004.

34. Vernon, B., Kim, S.W., Bae, Y.H. Thermoreversible copolymer gels for extracellular matrix. J Biomed Mater Res 51, 69, 2000.

35. Shapiro, A.M., Lakey, J.R., Ryan, E.A., et al. Islet transplantation in seven patients with type 1 diabetes mellitus using a glucocorticoid-free immunosuppressive regimen. $\underline{\mathrm{N}}$ Engl J Med 343, 230, 2000.

36. Orive, G., Gascâon, A.R., Hernâandez, R.M., et al. The search for new beta-cell sources. Trends Biotechnol 22, 612, 2004.

37. Matsumoto, S., Okitsu, T., Iwanaga, Y., et al. Insulin independence after living-donor distal pancreatectomy and islet allotransplantation. Lancet 365, 1642, 2005.

38. Nir, T., Dor, Y. How to make pancreatic beta cells-prospects for cell therapy in diabetes. Curr Opin Biotechnol 16, 524, 2005.

39. Zhang, Y.Q., Kritzik, M., Sarvetnick, N. Identification and expansion of pancreatic stem/progenitor cells. $\underline{\mathrm{J} \text { Cell Mol }}$ Med 9, 331, 2005.

40. Zhang, Y.Q., Sarvetnick, N. Development of cell markers for the identification and expansion of islet progenitor cells. Diabetes Metab Res Rev 19, 363, 2003.
41. Bodnar, C.A., Sen, A., Kallos, M.S., et al. Characterization of human islet-like structures generated from pancreatic precursor cells in culture. Biotechnol Bioeng 93, 980, 2006.

42. Hao, E., Tyrberg, B., Itkin-Ansari, P., et al. Beta-cell differentiation from nonendocrine epithelial cells of the adult human pancreas. Nat Med 12, 310, 2006.

43. Otonkoski, T., Gao, R., Lundin, K. Stem cells in the treatment of diabetes. Ann Med 37, 513, 2005.

44. Brolâen, G.K., Heins, N., Edsbagge, J., et al. Signals from the embryonic mouse pancreas induce differentiation of human embryonic stem cells into insulin-producing betacell-like cells. Diabetes 54, 2867, 2005.

45. Lumelsky, N., Blondel, O., Laeng, P., et al. Differentiation of embryonic stem cells to insulin-secreting structures similar to pancreatic islets. Science 292, 1389, 2001.

46. Di Gioacchino, G., Di Campli, C., Zocco, M.A., et al. Transdifferentiation of stem cells in pancreatic cells: state of the art. Transplant Proc 37, 2662, 2005.

47. Murtaugh, L.C., Law, A.C., Dor, Y., et al. Beta-catenin is essential for pancreatic acinar but not islet development. Development 132, 4663, 2005.

48. Lammert, E., Gu, G., McLaughlin, M., et al. Role of VEGF-A in vascularization of pancreatic islets. Curr Biol 13, 1070, 2003.

49. Lammert, E., Cleaver, O., Melton, D. Induction of pancreatic differentiation by signals from blood vessels. Science 294, 564, 2001.

50. Vaca, P., Martâin, F., Vegara-Meseguer, J.M., et al. Induction of differentiation of embryonic stem cells into insulinsecreting cells by fetal soluble factors. Stem Cells 24, 258, 2006.

51. Soria, B., Roche, E., Reig, J.A., et al. Generation of insulinproducing cells from stem cells. Novartis Found Symp 265, 158, 2005.

52. Leâon-Quinto, T., Jones, J., Skoudy, A., et al. In vitro directed differentiation of mouse embryonic stem cells into insulin-producing cells. Diabetologia 47, 1442, 2004.

53. Hori, Y., Gu, X., Xie, X., et al. Differentiation of insulinproducing cells from human neural progenitor cells. PLoS Med. 2, e103, 2005.

54. Burns, C.J., Minger, S.L., Hall, S., et al. The in vitro differentiation of rat neural stem cells into an insulin-expressing phenotype. Biochem Biophys Res Commun 326, 570, 2005.

55. Kodama, S., Kèuhtreiber, W., Fujimura, S., et al. Islet regeneration during the reversal of autoimmune diabetes in NOD mice. Science 14 302, 1223, 2003.

56. Itkin-Ansari, P., Levine, F. Sources of beta-cells for human cell-based therapies for diabetes. Cell Biochem Biophys 40, 103, 2004.

57. Fleischer, N., Chen, C., Surana, M., et al. Functional analysis of a conditionally transformed pancreatic beta-cell line. Diabetes 47, 1419, 1998.

58. Milo-Landesman, D., Surana, M., Berkovich, I., et al. Correction of hyperglycemia in diabetic mice transplanted with reversibly immortalized pancreatic beta cells controlled by the tet-on regulatory system. Cell Transplant 10, 645, 2001.

59. Simpson, N.E., Khokhlova, N., Oca-Cossio, J.A., et al. Effects of growth regulation on conditionally-transformed alginate-entrapped insulin secreting cell lines in vitro. Biomaterials 26, 4633, 2005. 
60. Ramiya, V., Schatz, D. Islet replacement vs. regeneration: hope or hype? Pediatr Diabetes. 5, 45, 2004.

61. Specke, V., Schuurman, H.J., Plesker, R., et al. Virus safety in xenotransplantation: first exploratory in vivo studies in small laboratory animals and non-human primates. Transpl Immunol 9, 281, 2002.

62. Chaudhari, M., Cornelius, J.G., Schatz, D., et al. Pancreatic stem cells: a therapeutic agent that may offer the best approach for curing type 1 diabetes. Pediatr Diabetes 2, 195, 2001.

63. Burns, C.J., Persaud, S.J., Jones, P.M. Stem cell therapy for diabetes: do we need to make beta cells? J Endocrinol 183, 437, 2004.

64. Contreras, J.L., Xie, D., Mays, J., et al. A novel approach to xenotransplantation combining surface engineering and genetic modification of isolated adult porcine islets. Surgery 136, 537, 2004.

65. Sattar, S.P., Shakeel, Ahmed, M., Majeed, F., et al. Inert medication ingredients causing nonadherence due to religious beliefs. Ann Pharmacother 38, 621, 2004.

66. Monaco, A.P., Maki, T., Ozato, H., et al. Transplantation of islet allografts and xenografts in totally pancreatectomized diabetic dogs using the hybrid artificial pancreas. Ann Surg 214, 339, 1991; discussion 361.

67. Sullivan, S.J., Maki, T., Borland, K.M., et al. Biohybrid artificial pancreas: long-term implantation studies in diabetic, pancreatectomized dogs. Science 252, 718, 1991.

68. Qi, M., Gu, Y., Sakata, N., et al. PVA hydrogel sheet macroencapsulation for the bioartificial pancreas. Biomaterials 25, 5885, 2004.

69. Chang, T.M. Semipermeable microcapsules. Science 146, 524, 1964.

70. Cruise, G.M., Hegre, O.D., Lamberti, F.V., et al. In vitro and in vivo performance of porcine islets encapsulated in interfacially photopolymerized poly(ethylene glycol) diacrylate membranes. Cell Transplant 8, 293, 1999.

71. Loscertales, I.G., Barrero, A., Guerrero, I., et al. Micro/nano encapsulation via electrified coaxial liquid jets. Science 295, 1695, 2002.

72. van Schilfgaarde, R., de Vos, P. Factors influencing the properties and performance of microcapsules for immunoprotection of pancreatic islets. J Mol Med 77, 199, 1999.

73. Marchetti, P., Del Prato, S., Lupi, R., et al. The pancreatic beta-cell in human type 2 diabetes. Nutrition, metabolism, and cardiovascular diseases. Nutr Metab Cardiovasc Dis 16, S3, 2006.

74. Nanji, S.A., Shapiro, A.M. Advances in pancreatic islet transplantation in humans. Diabetes Obes Metab 8, 15, 2006.

75. Cleveland, J.C., Jr., Raeburn, C., Harken, A.H. Clinical applications of ischemic preconditioning: from head to toe. Surgery 129, 664, 2001.

76. Toosy, N., McMorris, E.L., Grace, P.A., et al. Ischaemic preconditioning protects the rat kidney from reperfusion injury. BJU Int 84, 489, 1999.

77. Bellmann, K., Wenz, A., Radons, J., et al. Heat shock induces resistance in rat pancreatic islet cells against nitric oxide, oxygen radicals and streptozotocin toxicity in vitro. J Clin Invest. 95, 2840, 1995.

78. Wright, J.R., Jr., Yang, H., Dooley, K.C. Tilapia-a source of hypoxia-resistant islet cells for encapsulation. Cell Transplant 7, 299, 1998.
79. Wang, W., Gu, Y., Tabata, Y., et al. Reversal of diabetes in mice by xenotransplantation of a bioartificial pancreas in a prevascularized subcutaneous site. Transplantation 73, 122, 2002.

80. Trivedi, N., Steil, G.M., Colton, C.K., et al. Improved vascularization of planar membrane diffusion devices following continuous infusion of vascular endothelial growth factor. Cell Transplant 9, 115, 2000.

81. de Groot, M., Schuurs, T.A., van Schilfgaarde, R. Causes of limited survival of microencapsulated pancreatic islet grafts. J Surg Res 121, 141, 2004.

82. Siebers, U., Horcher, A., Bretzel, R.G., et al. Transplantation of free and microencapsulated islets in rats: evidence for the requirement of an increased islet mass for transplantation into the peritoneal site. Int J Artif Organs 16, 96, 1993.

83. Dufrane, D., Steenberghe, M., Goebbels, R.M., et al. The influence of implantation site on the biocompatibility and survival of alginate encapsulated pig islets in rats. Biomaterials 27, 3201, 2006.

84. Schneider, S., von Mach, M.A., Kraus, O., et al. Intraportal transplantation of allogenic pancreatic islets encapsulated in barium alginate beads in diabetic rats. Artif Organs 27, 1053, 2003.

85. Toso, C., Morel, P., Bucher, P., et al. Insulin independence after conversion to tacrolimus and sirolimus-based immunosuppression in islet-kidney recipients. Transplantation 15 76, $1133,2003$.

86. Toso, C., Oberholzer, J., Ceausoglu, I., et al. Intra-portal injection of 400-microm microcapsules in a large-animal model. Transpl Int 16, 405, 2003.

87. De Vos, P., De Haan, B.J., Wolters, G.H., et al. Improved biocompatibility but limited graft survival after purification of alginate for microencapsulation of pancreatic islets. Diabetologia 40, 262, 1997.

88. King, A., Lau, J., Nordin, A., et al. The effect of capsule composition in the reversal of hyperglycemia in diabetic mice transplanted with microencapsulated allogeneic islets. Diabetes Technol Ther 5, 653, 2003.

89. King, A., Sandler, S., Andersson, A. The effect of host factors and capsule composition on the cellular overgrowth on implanted alginate capsules. J Biomed Mater Res 57, 374, 2001.

90. Fritschy, W.M., de Vos, P., Groen, H., et al. The capsular overgrowth on microencapsulated pancreatic islet grafts in streptozotocin and autoimmune diabetic rats. Transpl Int $\mathbf{7}$, 264, 1994.

91. De Vos, P., De Haan, B., Van Schilfgaarde, R. Effect of the alginate composition on the biocompatibility of alginatepolylysine microcapsules. Biomaterials 18, 273, 1997.

92. Lee, D.Y., Nam, J.H., Byun, Y. Effect of polyethylene glycol grafted onto islet capsules on prevention of splenocyte and cytokine attacks. J Biomater Sci Polym Ed 15, 753, 2004.

93. Siebers, U., Horcher, A., Brandhorst, H., et al. Analysis of the cellular reaction towards microencapsulated xenogeneic islets after intraperitoneal transplantation. J Mol Med 77, 215, 1999.

94. Gray, D.W. An overview of the immune system with specific reference to membrane encapsulation and islet transplantation. Ann N Y Acad Sci 944, 226, 2001. 
95. Omer, A., Keegan, M., Czismadia, E., et al. Macrophage depletion improves survival of porcine neonatal pancreatic cell clusters contained in alginate macrocapsules transplanted into rats. Xenotransplantation 10, 240, 2003.

96. Contreras, J.L., Bilbao, G., Smyth, C.A., et al. Cytoprotection of pancreatic islets before and early after transplantation using gene therapy. Kidney Int 61(1 Suppl), 79, 2002.

97. Rabinovitch, A., Suarez-Pinzon, W., Strynadka, K., et al. Transfection of human pancreatic islets with an anti-apoptotic gene (bcl-2) protects beta-cells from cytokine-induced destruction. Diabetes 48, 1223, 1999.

98. Saldeen, J. Cytokines induce both necrosis and apoptosis via a common Bcl-2-inhibitable pathway in rat insulinproducing cells. Endocrinology 141, 2003, 2000.

99. Wiegand, F., Kroncke, K.D., Kolb-Bachofen, V. Macrophagegenerated nitric oxide as cytotoxic factor in destruction of alginate-encapsulated islets. Protection by arginine analogs and/or coencapsulated erythrocytes. Transplantation 56, 1206, 1993.

100. Yang, H., Wright, J.R., Jr. Co-encapsulation of Sertoli enriched testicular cell fractions further prolongs fish-to-mouse islet xenograft survival. Transplantation 27 67, 815, 1999.

101. Chae, S.Y., Kim, S.W., Bae, Y.H. Effect of cross-linked hemoglobin on functionality and viability of microencapsulated pancreatic islets. Tissue Eng 8, 379, 2002.

102. Chae, S.Y., Lee, M., Kim, S.W., et al. Protection of insulin secreting cells from nitric oxide induced cellular damage by crosslinked hemoglobin. Biomaterials 25, 843, 2004.

103. Sigrist, S., Mechine-Neuville, A., Mandes, K., et al. Influence of VEGF on the viability of encapsulated pancreatic rat islets after transplantation in diabetic mice. Cell Transplant 12, 627, 2003.

104. Sigrist, S., Mechine-Neuville, A., Mandes, K., et al. Induction of angiogenesis in omentum with vascular endothelial growth factor: influence on the viability of encapsulated rat pancreatic islets during transplantation. J Vasc Res 40, 359, 2003.

105. Lai, Y., Schneider, D., Kidszun, A., et al. Vascular endothelial growth factor increases functional beta-cell mass by improvement of angiogenesis of isolated human and murine pancreatic islets. Transplantation 79, 1530, 2005.

106. Stagner, J., Mokshagundam, S., Wyler, K., et al. Beta-cell sparing in transplanted islets by vascular endothelial growth factor. Transplant Proc 36, 1178, 2004.

107. Hulinsky, I., Harrington, J., Cooney, S., et al. Insulin secretion and DNA synthesis of cultured islets of Langerhans are influenced by the matrix. Pancreas 11, 309, 1995.
108. Hulinsky, I., Cooney, S., Harrington, J., et al. In vitro growth of neonatal rat islet cells is stimulated by adhesion to matrix. Horm Metab Res 27, 209, 1995.

109. Lee, D.Y., Park, S.J., Nam, J.H., et al. A new strategy toward improving immunoprotection in cell therapy for diabetes mellitus: long-functioning PEGylated islets in vivo. Tissue Eng 12, 615, 2006.

110. Ikeda, H., Kobayashi, N., Tanaka, Y., et al. A newly developed bioartificial pancreas successfully controls blood glucose in totally pancreatectomized diabetic pigs. Tissue Eng 12, 1799, 2006.

111. Cirulli, V., Beattie, G.M., Klier, G., et al. Expression and function of alpha(v)beta(3) and alpha(v)beta(5) integrins in the developing pancreas: roles in the adhesion and migration of putative endocrine progenitor cells. J Cell Biol 150, 1445, 2000.

112. Kantengwa, S., Baetens, D., Sadoul, K., et al. Identification and characterization of alpha 3 beta 1 integrin on primary and transformed rat islet cells. Exp Cell Res 237, 394, 1997.

113. Ris, F., Hammar, E., Bosco, D., et al. Impact of integrinmatrix matching and inhibition of apoptosis on the survival of purified human beta-cells in vitro. Diabetologia 45, 841, 2002.

114. Hammar, E.B., Irminger, J.C., Rickenbach, K., et al. Activation of NF-kappaB by extracellular matrix is involved in spreading and glucose-stimulated insulin secretion of pancreatic beta cells. J Biol Chem 280, 30630, 2005.

115. Pinkse, G.G., Bouwman, W.P., Jiawan-Lalai, R., et al. Integrin signaling via RGD peptides and anti-beta1 antibodies confers resistance to apoptosis in islets of Langerhans. Diabetes 55, 312, 2006.

116. Nagata, N., Gu, Y., Hori, H., et al. Evaluation of insulin secretion of isolated rat islets cultured in extracellular matrix. Cell Transplant 10, 447, 2001.

117. Close, N., Anand, R., Hering, B., et al. NIH-supported national islet transplantation registry. Cell Biochem Biophys 40(3 Suppl), 9, 2004.

Address reprint requests to: Kytai T. Nguyen Department of Bioengineering University of Texas at Arlington 501 West First Street, ELB-220 Arlington, TX 76019

E-mail: knguyen@uta.edu 



\section{This article has been cited by:}

1. Seung-Hee Lee, Ergeng Hao, Alexei Y. Savinov, Ifat Geron, Alex Y. Strongin, Pamela Itkin-Ansari. 2009. Human $\beta$-cell Precursors Mature Into Functional Insulin-producing Cells in an Immunoisolation Device: Implications for Diabetes Cell Therapies. Transplantation 87:7, 983-991. [CrossRef]

2. Xulang Zhang, Yubing Xie, Chee Guan Koh, L. James Lee. 2009. A novel 3-D model for cell culture and tissue engineering. Biomedical Microdevices . [CrossRef]

3. Xiao-Di Yang, Hong-Ming Li, Miao Chen, Xiang-Hui Zou, Lin-Yun Zhu, Chi-ju Wei, Guo-Qiang Chen. 2009. Enhanced insulin production from murine islet beta cells incubated on poly(3-hydroxybutyrate- co -3-hydroxyhexanoate). Journal of Biomedical Materials Research Part A 9999A, NA-NA. [CrossRef]

4. Davide Mineo, Junichiro Sageshima, George W. Burke, Camillo Ricordi. 2009. Minimization and withdrawal of steroids in pancreas and islet transplantation. Transplant International 22:1, 20-37. [CrossRef]

5. John J. Schmidt, Jon Rowley, Hyun Joon Kong. 2009. Hydrogels used for cell-based drug delivery. Journal of Biomedical Materials Research Part A 87A:4, 1113-1122. [CrossRef]

6. Kai-Chiang Yang, Chang-Chin Wu, Feng-Huei Lin, Zhi Qi, Tzong-Fu Kuo, Yung-Hsin Cheng, Moon-Pei Chen, Shoichiro Sumi. 2008. Chitosan/gelatin hydrogel as immunoisolative matrix for injectable bioartificial pancreas. Xenotransplantation 15:6, 407-416. [CrossRef]

7. John C. Pickup, Zheng-Liang Zhi, Faaizah Khan, Tania Saxl, David J. S. Birch. 2008. Nanomedicine and its potential in diabetes research and practice. Diabetes/Metabolism Research and Reviews 24:8, 604-610. [CrossRef]

8. C.M. Metallo, S.M. Azarin, L. Ji, J.J. de Pablo, S.P. Palecek. 2008. Engineering tissue from human embryonic stem cells. Journal of Cellular and Molecular Medicine 12:3, 709-729. [CrossRef]

9. David A. Taylor-Fishwick, Gary L. Pittenger, Aaron I. Vinik. 2008. Transplantation and beyond. Drug Development Research 69:3, 165-176. [CrossRef]

10. Priyesh Patel, Scott Irvine, Jean R. McEwan, Suwan N. Jayasinghe. 2008. Bio-protocols for directly forming active encapsulations containing living primary cells. Soft Matter 4:6, 1219. [CrossRef] 